\title{
Study and Practice on the Talent Training Model of Applied Electronical Technology Specialty
}

\author{
Yongliang Zhang ${ }^{\mathrm{a}}$, Bing $\mathrm{Luo}^{\mathrm{b}}$ and Wenhua Qiuc \\ School of Information Engineering, Guangdong Mechanical and Electrical College, Guangzhou \\ 510550, China. \\ azherac@163.com, b32999148@qq.com, c27175013@qq.com
}

\begin{abstract}
With the transformation and upgrading of the industrial structure and the transformation of the economic driving factors, the electronic information industry is becoming more and more demand for the technical and skilled talents in higher vocational colleges. So taking the construction and development of the application of electronic technology in our school as an example, the professional positioning, teaching management and personnel training quality assurance system are introduced in the paper, and we eagerly hope that professional experience can provide reference for the reform of similar professional talents training mode in other vocational colleges.
\end{abstract}

Keywords: Industrial structure; transformation and upgrading; technical and skilled talents; talents training mode.

\section{应用电子技术专业人才培养模式研究与实践}

\author{
张永亮, 罗兵, 邱文华 \\ 广东机电职业技术学院信息工程学院, 广州, 广东省 中国
}

摘 要: 伴随着产业结构的转型升级和经济驱动要素的转变, 电子信息产业对高职院校技术技 能型人才的要求越来越高。本文以我校应用电子技术专业建设和发展为例, 详细介绍了专业 的定位、教学管理和人才培养质量保障体系, 以期对其他高职院校同类专业人才培养模式改 革提供借鉴。

关键词: 产业结构; 转型升级; 技术技能人才; 人才培养模式

\section{1. 前言}

电子信息产业是国民经济的战略性、基础性和先导性支柱产业，是我国经济最具活力、 最具创新的行业之一 ${ }^{[1]}$ 。国家 “十二五” 规划纲要指出：大力发展新一代信息技术、新能源汽 车等七大战略性新型产业; 国务院《珠江三角洲地区改革发展规划纲要 (2008-2020)》提出: 支持珠江三角洲地区与港澳地区在现代服务业领域的深度合作，重点发展电子信息领域软件 及集成电路设计、新型平板显示、数字家庭等产业, 建设现代信息产业基地 ${ }^{[2]}$; 广州市也明确 提出：做大做强电子信息产业, 实施《广州信息产业国家高技术产业基地发展总体规划》, 围绕培育自主知识产权，提高自主创新能力，着力发展高端电子信息制造和现代信息服务业。 当前, 新一轮科技革命和产业变革蓄势待发, 社会信息化将深入发展, 这为我国电子信息产 业的大发展提供了广阔发展空间。可以说，我国电子信息产业将在 “十三五” 时期迎来新的 发展机遇和发展空间, 也面临新一轮产业升级及市场竞争的严峻挑战。

鉴于此, 高职院校电子信息类专业必须要适应当前经济发展新常态, 服务创新驱动发展 战略, 培养一批具备扎实的专业知识、较强的实践能力、良好的职业素养, 能服务产业转型 升级和企业技术创新需要的发展型、复合型和创新型的高级技术技能人才。 


\section{2. 我校应用电子技术专业概况}

我校应用电子技术专业是广东省 2006 年示范性建设专业, 2010 年确定为省示范专业, 2011 年获批中央财政支持的职业教育实训基地建设项目, 2012 年获批一个省级大学生校外实践基 地。现有在校生 283 人, 校内专任教师 18 人, 其中正高 4 人, 副高 7 人, 博士 2 人, 高级职 称占 $61.1 \%$ 。专业设有 EDA 技术、嵌入式技术、强制认证等校内实训室 13 个, 仪器设备总值 800 多万, 与广州健马电器有限公司共建 “校中厂”, 与广东好帮手电子科技股份有限公司共 建 “厂中校” ; 近三年专业学生在全国电子设计大赛、挑战杯、职业技能竞赛中获得省级以 上奖励 50 多项，毕业生顶岗实习对口率 $100 \%$ ，一次就业率超过 99. $0 \%$, 人才培养质量不断提 升。专业建设立足珠三角, 服务广东区域经济发展和产业转型升级, 实施 “校企合作、协同 创新” 战略, 坚持走质量、效益协调发展之路, 其专业综合实力位居广东省同类专业前三, 处于全国领先水平。

\section{3. 专业建设的经验和突出特色}

\section{1 . 专业建设思路}

应用电子技术专业自设立以来始终以校企合作长效机制建设为先导, 以广东省发展高端 新型电子信息产业人才需求为依据, 通过 “校企结合搭平台、工学结合塑能力、证赛融合提 质量、四段递进促就业” 全面提高人才培养质量和专业建设水平，如图1所示。

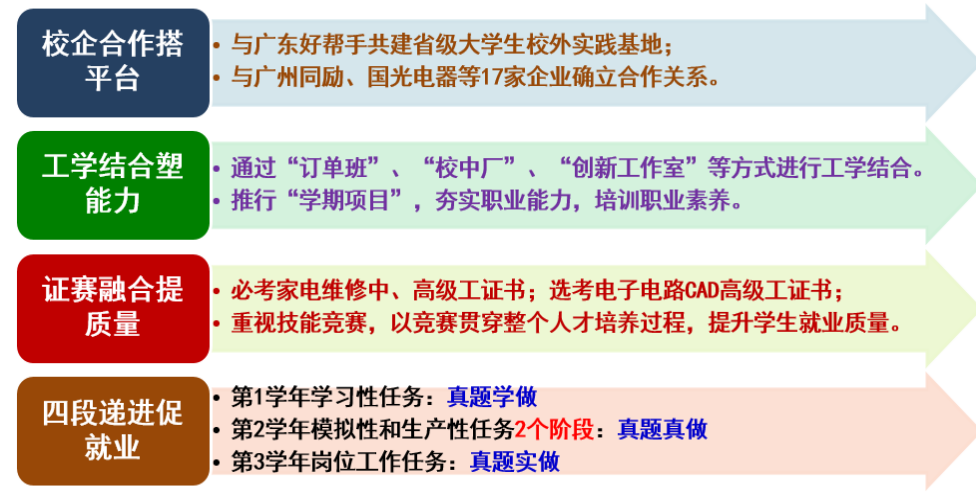

图1 专业建设思路

在校企结合搭平台方面：与广东好帮手电子科技股份有限公司共建省级大学生校外实践 基地 ${ }^{[3]}$; 与广州同励认证咨询有限公司、索尼华南电子有限公司、广州国光电器等 23 家企业确 立合作关系。

在工学结合塑能力方面: 通过 “订单班”、“校中厂”、“厂中校” 等方式进行工学结 合 ${ }^{[4-5]}$; 依托应用电子技术中央财政实训基地与广州同励联合开展质量检测、强制认证专项技 能训练; 借鉴新加坡经验, 实施 “学期项目” ，夯实职业能力，培养职业素养 ${ }^{[6]}$ 。

在证赛融合提质量方面: 要求学生双证毕业, 必考家电维修中、高级工证书; 选考电子 电路CAD高级工证书; 以竞赛贯穿整个人才培养过程, 提升学生就业竞争力。

在四段递进促就业方面: 第1学年学习性任务: 真题学做; 第2学年模拟性和生产性任务2 个阶段：真题真做；第3学年岗位工作任务：真题实做。

\section{2. 教学管理和质量评价}

通过对珠三角地区电子电器产品制造行业的岗位设置和人才需求的调研分析确定本专业 的毕业生从事的主要工作岗位及岗位群为电子电器产品开发、品质管理、产品认证、产品维 修、技术支持等。因此, 为了保证应用电子技术专业人才培养质量, 整个专业的课程体系可 划分为公共基础课、专业课和拓展课三大类。在学生培育过程中, 由专业基础课向专业课程 逐步深入, 由理论课程向实践的拓展课程逐步深入, 辅以家用电子产品维修中、高级工考证, 进一步提升和巩固学生的专业技能。 
在教学管理和质量评价制度建设方面，实行专业指导委员会、专业带头人、课程负责人、 任课教师四级审核制度以及教学督导评价、任课教师互评、领导评价、学生评价四元评价的 体制，如图2所示。

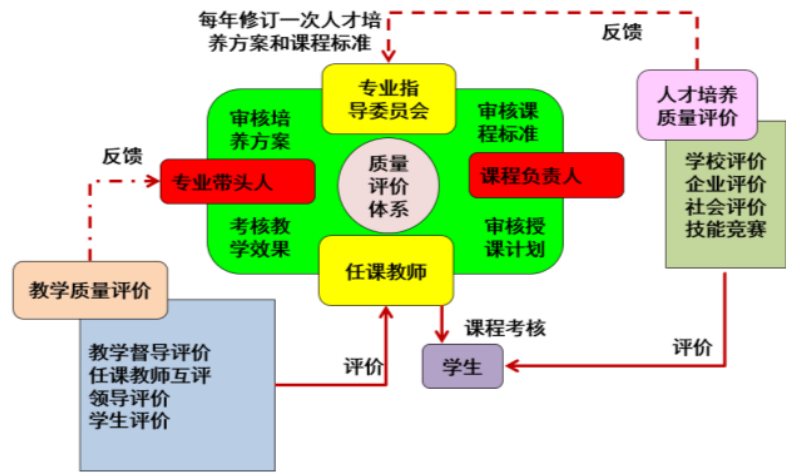

3. 3. 校企合作机制

图2 教学管理与质量评价制度建设

依托广东机电职教集团，应用电子技术专业与广东好帮手、国光电器、广州同励等企业 搭建了校企合作平台, 并形成了人才共育、过程共管、责任共担、成果共享的校企合作机制, 如图3所示。通过聘请企业带头人成立专业建设指导委员会, 聘请企业具有丰富工作经验和具 有一定职称的企业员工作为兼职教师、组织学生去企业顶岗实习、推荐学生就业等途径全面 提高人才培养质量。

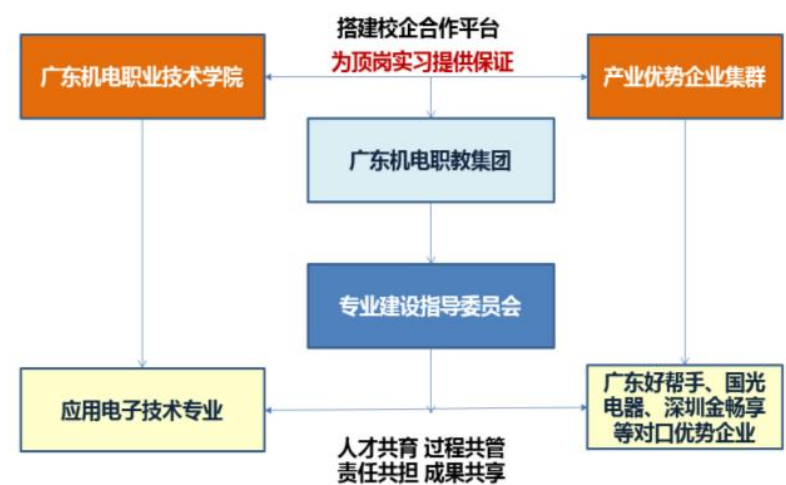

\section{4. 毕业生社会评价}

图3 应用电子技术专业校企合作机制建设

为了解我院毕业生走上工作岗位后的工作情况，掌握用人单位对学生思想品德、精神风 貌、知识水平、工作能力和人际交往能力等方面的评价, 全面了解我院毕业生的就业状况和 就业质量, 掌握社会各界、用人单位、校友对本院教育教学质量、人才培养和毕业生能力要 求的综合评价, 提高在校学生的综合素质, 为学院的教育教学改革、专业建设和招生计划的 制定以及有针对性地开展学生思想教育、为就业指导服务提供现实依据, 并为开辟新的毕业 生就业市场奠定基础, 每年专业都针对毕业生进行就业情况调查。根据书面问卷调查结果, 许多用人单位充分肯定了专业教学工作所取得的优异成绩。2015届毕业生评价情况分别如图 4、图5、图6所示。

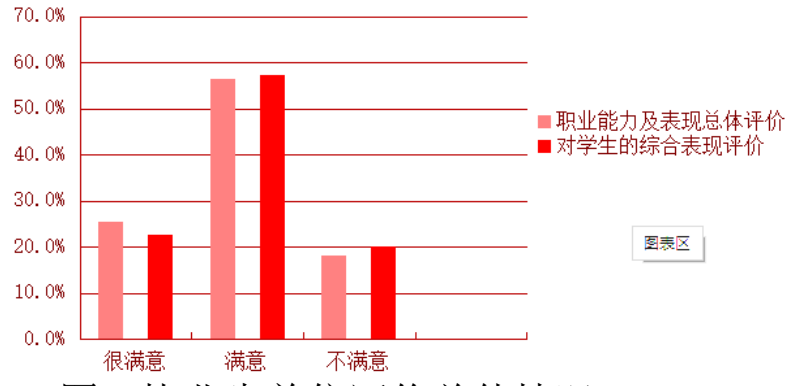

图4 毕业生单位评价总体情况

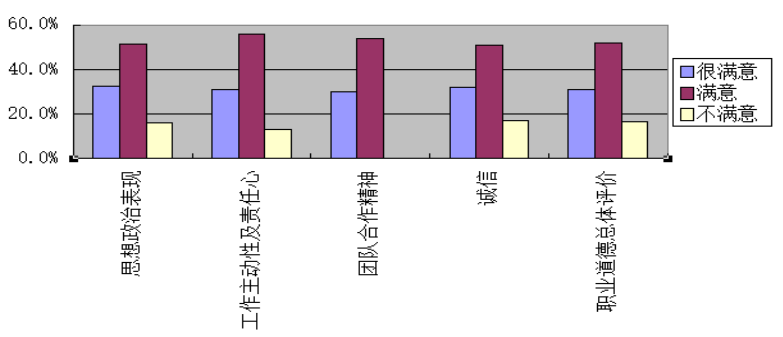

图5 单位对毕业生职业道德评价情况 


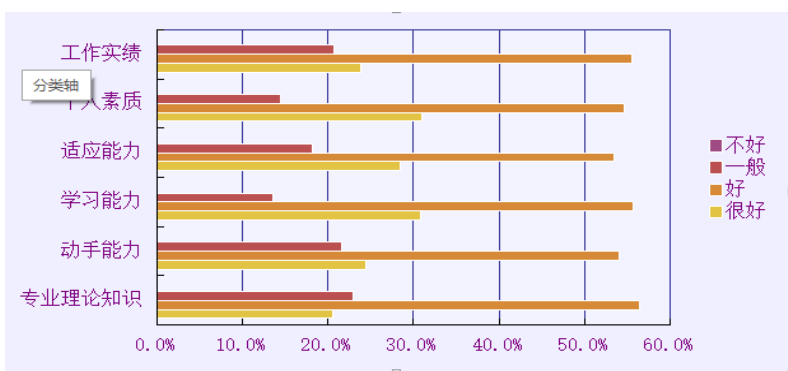

图6 用人单位对毕业生专业能力评价情况

\section{4. 结语}

2015年, 我校应用电子技术专业成功申请为国家级品牌专业, 围绕 “国内领先、国际一 流” 的建设目标, 专业的发展必须要适应当前经济发展新常态, 服务创新驱动发展战略, 紧 跟新工业革命背景下, 以信息技术与制造业加速融合为主要特征的智能制造成为全球制造业 的主要趋势, 加快培养从事电子产品强化检测、质量管理和国际安全认证以及智能电子产品 系统设计、“互联网+” 应用的高素质创新型技术技能人才, 以满足经济社会发展的需求, 助 力产业升级。

\section{致谢}

本文为 2014 年度广东省教育教学成果奖 (高等教育) 培育项目《广东机电职业技术学院广东好帮手电子科技股份有限公司实践教学基地》、2014年度广东省高等职业教育教学改革 项目《“订单班” 人才培养模式研究与实践一以应用电子技术专业为例》(201401059)、广东 省教育科研 “十二五” 规划2013年度课题《以技能竞赛引领电子信息类专业高级技术技能人 才培养的研究与实践》 (2013JK200)、广东省应用电子技术高等职业教育品牌专业专项资金项 目的阶段性成果之一。

\section{References}

[1]. Electronic Information Division. Interpretation of China's manufacturing 2025: building a modern electronic information industry system support services made in China 2025, http://www.miit.gov.cn/n11293472/n11295210/n11298313/16644241.html.

[2]. People's Government of Guangdong Province. Outline of reform and development plan for the Pearl River Delta region (2008-2020). http://zwgk.gd.gov.cn/006939748/201110/t2011100928 5276.html.

[3]. W. G. Pan, H. M. Cai, Y. G. Li. Research on developing skilled personnel by mutual cooperation between school and factory. Advanced Materials Research, vol. 271-273(2011), p.1941-1945.

[4]. Y. L. Zhang, J. L. Zhong, W. H. Qiu and B. Luo. The Training Mode Reform of "Cogent-Jidian" Students Practice Base Based on Depth School-enterprise Cooperation. Advanced in Social and Behavioral Sciences, vol. 6(2014), p. 91-95.

[5]. M. Q. Lu. Training base construction and research in higher vocational school based on order class. Experimental Technology and Management, vol. 32(2015), p. 210-212.

[6]. L. X. Gao, Y. L. Zhang. Research and Practice of Term Project Personal Training Mode. Journal of Hubei Industrial Polytechnic, vol. 28(2015), p. 12-16. 